\title{
Primary thoracic synovial sarcoma: Factors affecting long-term survival
}

\author{
Domenico Galetta, MD, ${ }^{a}$ Giuseppe Pelosi, MD, ${ }^{\text {b,c }}$ Francesco Leo, MD, ${ }^{a}$ Piergiorgio Solli, MD, ${ }^{a}$ Giulia Veronesi, MD, \\ Alessandro Borri, MD, ${ }^{a}$ Roberto Gasparri, MD, ${ }^{a}$ Francesco Petrella, MD, ${ }^{a}$ Clementina Di Tonno, MD, ${ }^{\text {b }}$ \\ Barbara Del Curto, DSc, and Lorenzo Spaggiari, MD, PhD, ${ }^{\mathrm{a}, \mathrm{c}}$ Milan, Italy
}

丹 Supplemental material is available online.

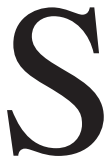

ynovial sarcoma is a malignant neoplasm predominantly affecting soft tissues of the extremities in adolescents and young adults and might rarely occur in other anatomic locations. The lung, mediastinum, pleura, and chest wall have also recently been found to be sites affected primarily by this sarcoma. ${ }^{1-3}$

We evaluated the clinical and pathologic features of primary synovial sarcoma (PSS) of the chest and the role of surgical intervention and tried to identify possible prognostic factors affecting survival.

\section{Clinical Summary}

Between October 1998 and December 2006, 15 patients ( 7 men) underwent a resection of PSSs of the chest, which were categorized into pulmonary, mediastinal, and chest wall PSSs according to the tumor location. Medical records of these patients were analyzed for age, sex, preoperative symptoms, radiologic findings, pathology, surgical procedures, clinical outcome, and long-term survival.

All pathologic slides were rereviewed, and PSSs were confirmed by means of immunohistochemical and fluorescence in situ hybridization studies. Fluorescence in situ hybridization analysis was performed for the identification of the diagnostic chromosomal translocation $(\mathrm{t}[\mathrm{X} ; 18][\mathrm{p} 11.2 ; \mathrm{q} 11.2])$, a marker for this tumor, resulting from fusion of the SYT gene on chromosome 18 to either the SSX1 or SSX2 gene on chromosome X.

Median age was 52 years (range, 21-77 years). Computed tomographic scans of the chest (Figure 1 and Figure E1) were performed in all patients and demonstrated a pulmonary mass in 8 patients, a mediastinal neoplasm in 2 patients (anterior and posterior, respectively), and a chest wall tumor in 5 patients. A positron

From the Divisions of Thoracic Surgery and Pathology and Laboratory

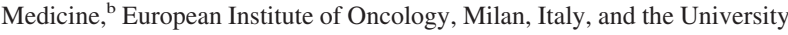
of Milan School of Medicine, ${ }^{\mathrm{c}}$ Milan, Italy.

Received for publication May 22, 2007; accepted for publication May 31, 2007.

Address for reprints: Domenico Galetta, MD, Division of Thoracic Surgery, European Institute of Oncology, Via Ripamonti 435, 20141, Milan, Italy (E-mail: mimgaletta@yahoo.it).

J Thorac Cardiovasc Surg 2007;134:808-9

$0022-5223 / \$ 32.00$

Copyright $\odot 2007$ by The American Association for Thoracic Surgery doi:10.1016/j.jtcvs.2007.05.036 emission tomographic scan was performed in 4 patients, showing high tumor activity in all of them (maximal standardized uptake value: range, 4.5-11.2; median, 6.6).

Surgical procedures included bilobectomy, pneumonectomy, and pleuropneumonectomy, respectively, in 1 patient each; lobectomy in 3 patients; chest wall resection in 5 patients; and wide wedge pulmonary resection and mediastinal tumor excision in 2 patients, respectively. Resection was complete in 9 $(60 \%)$ patients.

Tumor size ranged from 3.5 to $21 \mathrm{~cm}$ (median, $8 \mathrm{~cm}$ ). Six tumors were larger than $10 \mathrm{~cm}$. Macroscopically, in 10 cases tumors presented as well-circumscribed masses. Histopathologic diagnosis confirmed a biphasic tumor in 1 patient (Figure E1, A and inset), monophasic fibrous tumors in 13 patients (Figure E1, $B$ ), and a poorly differentiated tumor in 1 patient (Figure E1, C). Thirteen patients showed diffuse immunoreactivity for epithelial membrane antigen and keratins. Bcl-2 and S-100 results were negative in all patients. The tumor was positive for $t(X ; 18)$ in all patients, confirming the diagnosis of synovial sarcoma (Figure E2, $C$, inset).

One $(6.6 \%)$ patient died postoperatively of adult respiratory distress syndrome. Major complications occurred in 3 patients (postoperative bleedings requiring reoperation). Minor complications included prolonged air leak in 3 patients and atelectasis in 2 patients. Median hospitalization was 7 days (range, 5-11 days). Eleven patients had postoperative adjuvant therapy (3 received chemotherapy, 1 received radiotherapy, and 7 received chemoradiotherapy).

Median follow-up was 25 months (range, 1-148 months). Local recurrence developed in 7 (46.6\%) patients, 2 (13.3\%) of whom had distant metastasis. The 5-year disease-free interval rate was $30 \%$ (median, 15 months). The 10-year survival rate was $33.5 \%$. Six (40\%) patients are currently alive, 3 (20\%) with disease (overall median survival, 27 months).

Factors that adversely affected survival include a tumor dimension of greater than $10 \mathrm{~cm}(P=.0062)$, incomplete resection $(P=$ $.0114)$, and no adjuvant therapy $(P=.035)$.

\section{Discussion}

PSSs involving the thorax are rare entities reported in the literature either as single observations or small series. ${ }^{1-4}$ They usually occur in adults, and the mean age at diagnosis is 38 years. $^{2}$ Our series showed that thoracic PSS is diagnosed at an average age of 52 years and showed no sex predilection. Our findings are in keeping with prior studies and emphasize that PSS of the chest belongs in the differential diagnosis of chest masses in young adults (localized fibrous tumors of the pleura, mesothelioma, fibrosarcoma, and metastatic disease). 


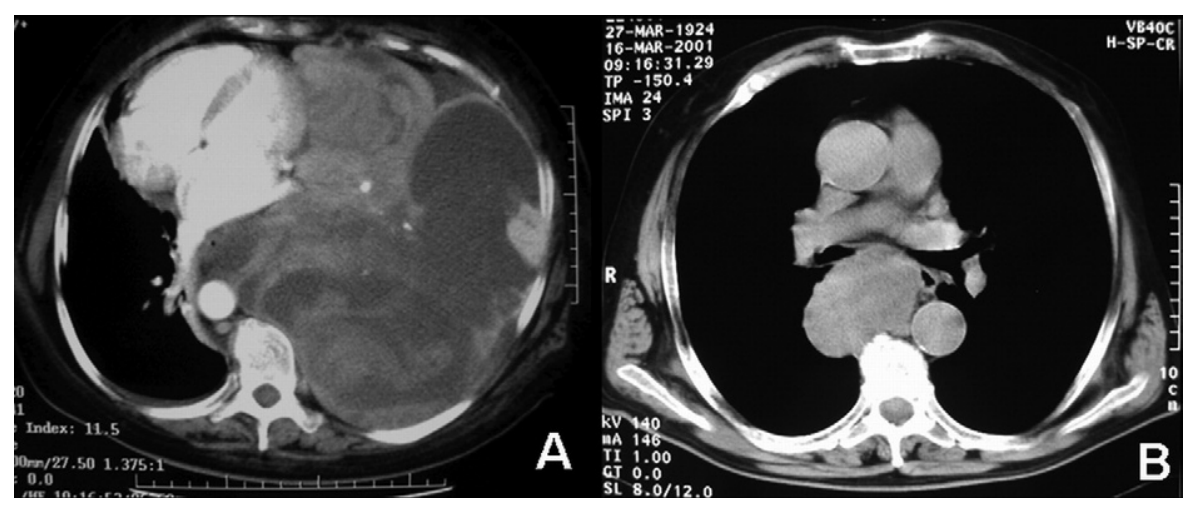

Figure 1. Computed tomographic scans showing pulmonary $(A)$ and mediastinal (B) localization of primary synovial sarcomas.

Immunohistochemical findings that distinguish synovial sarcoma from other sarcomas include positive staining for cytokeratin and EMA. Synovial sarcomas lack staining for S-100 and smooth muscle markers.

Optimal treatment of PSS of the chest has not been defined. Multimodal therapy of surgical intervention, chemotherapy, and radiotherapy has been used. Recurrences are likely and might be treated with further resection when possible or with radiotherapy. In our series chemotherapy and radiotherapy helped to control the recurrences, with a long disease-free survival.

In conclusion, thoracic PSS is a very uncommon and aggressive malignancy with poor prognosis. The best treatment is not yet defined. Complete resection is feasible and leads to an acceptable local control and long-term survival.

\section{References}

1. Zeren H, Moran CA, Suster S, Fishback NF, Koss MN. Primary pulmonary sarcomas with features of monophasic synovial sarcoma: a clinicopathologic, immunohistochemical, and ultrastructural study of 25 cases. Hum Pathol. 1995;26:474-80.

2. Duran-Mendicuti A, Costello P, Vargas SO. Primary synovial sarcoma of the chest: radiographic and clinicopathologic correlation. J Thorac Imaging. 2003; 18:87-93.

3. Nicholson AG, Goldstraw P, Fisher C. Synovial sarcoma of the pleura and ist differentiation from other primary pleural tumors: a clinicopathologic and immunohistochemical review of three cases. Histopathology. 1998;33:508-13.

4. Beguéret H, Galateau-Salle F, Guillou L, Chetaille B, Brambilla E, Vignaud J-M, et al. Primary intrathoracic synovial sarcoma. A clinicopathologic study of $40 \mathrm{t}(\mathrm{X} ; 18)$-positive cases from the French Sarcoma group and the Mesopath group. Am J Surg Pathol. 2005;29:339-46. 


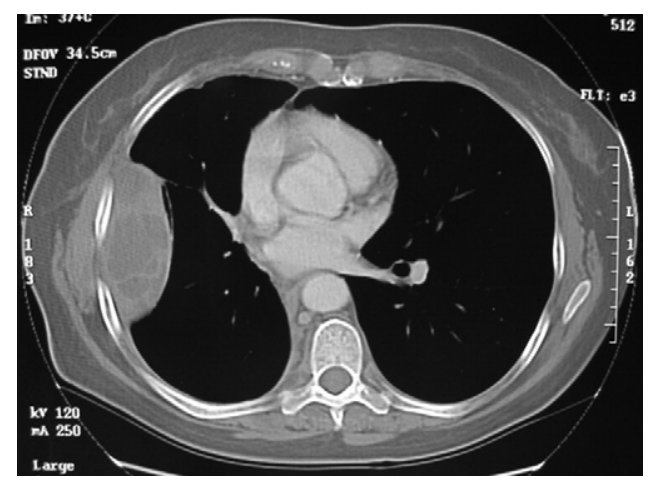

Figure E1. Computed tomographic scan showing chest wall localization of primary synovial sarcoma.
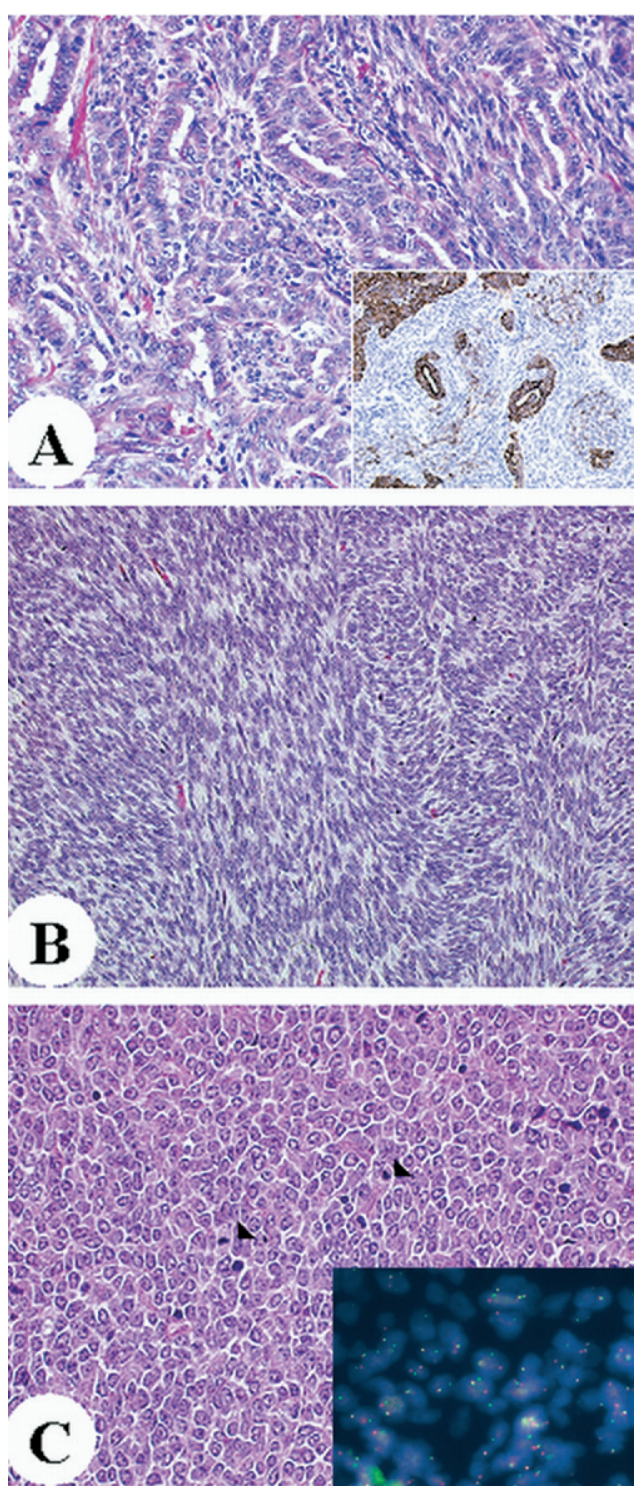

Figure E2. Histologic features of synovial sarcoma of the lung showing a biphasic tumor with glandular epithelial aggregates intermingled with spindle cells and highlighted by cytokeratin immunoreactivity ( $A$, inset), a monophasic fibrous tumor composed entirely of short spindle cells (B), and a poorly differentiated tumor composed of more atypical, spindle to rounded cells with high mitotic count (C, arrowheads). Fluorescence in situ hybridization analysis documents $\mathrm{t}(\mathbf{1 8 q 1 1 . 2 )}$. Tumor cells show one orange and one green signal, which are indicative of a rearrangement of one copy of the $S Y T$ gene region (C, inset). 